\title{
Hepatitis C virus infection in Saskatchewan First Nations communities: Challenges and innovations
}

\author{
S Skinner ${ }^{1}$, G Cote $^{2}$, I Khan ${ }^{3 *}$
}

\begin{abstract}
Hepatitis $\mathrm{C}$ virus ( $\mathrm{HCV}$ ) infection has become a major public health issue in Canada, and especially in Saskatchewan First Nations (FNs) communities. One of the challenges in eliminating hepatitis $C$ in Canada is accessing hard-to-reach populations, such as FNs people living on reserves. In Canada, $\mathrm{HCV}$ is a notifiable disease but complete and timely surveillance of HCV data is not always possible in remote communities. In addition, national surveillance data are insufficient for determining the number of cases of hepatitis $C$ among FNs populations, because many provinces do not collect information according to ethnicity. Statistics for FN communities are available federally through the First Nations and Inuit Health Branch (FNIHB) in partnership with the communities and the province. There are multiple factors associated with the high rates of HCV in FNs communities, including barriers in accessing preventive services, early diagnosis and treatment. These access issues are largely attributable to issues with geographical remoteness, transportation, education and awareness, and a health care system designed around urban health. New and innovative ways of delivering information and services, such as the mobile hepatitis C clinic (Liver Health Days) and the community-driven Sexually Transmitted Bloodborne Infections (STBBI) Know Your Status program, are proving invaluable in remote FNs communities. Extending these in-community and community-driven programs to other FNs communities and to the prison population could be invaluable in working towards the World Health Organization elimination goals of hepatitis $C$ virus for all.
\end{abstract}

\author{
Affiliations \\ 1 Regina Infectious Disease \\ Clinic, Department of Medicine, \\ University of Saskatchewan, \\ Saskatoon, SK \\ ${ }^{2}$ Chief of Cote First Nation, SK \\ ${ }^{3}$ First Nation Inuit Health Branch \\ Regina Office, Department of \\ Indigenous Services Canada, \\ Saskatchewan Region, Regina, SK
} *Correspondence: ibrahim.khan@
canada.ca

Suggested citation: Skinner S, Cote G, Khan I. Hepatitis C virus infection in Saskatchewan First Nations communities: Challenges and innovations. Can Commun Dis Rep 2018;44(7/8):173-8. https://doi.org/10.14745/ ccdr.v44i78a04

Keywords: Hepatitis C virus, First Nations and remote communities, prison populations, awareness, diagnosis, treatment, prevention

\section{Introduction}

Approximately 170 million people worldwide are chronically infected with hepatitis C virus (HCV) (1-6). In Canada, 250,000 to 275,000 are chronically infected with $\mathrm{HCV}$ and an upward trend of both infection and HCV-associated liver diseases was reported nationally (1-3,7-12). Until recently an estimated 15,800 persons were living with cirrhosis and 5,500 with liver failure in 2017. It has been estimated that from 2007 to 2027 , the number of prevalent cases of cirrhosis will increase from 15,814 to 17,570 and carcinoma will increase from 338 to 379 cases (13). The impact of HCV and the sequelae of hepatitis $\mathrm{C}$ infection on the health of Canadians are considerable in terms of the impact of chronic liver failure, liver transplant and early death (13).

\section{Injection drug use is the most common risk factor for} hepatitis $C(7-10,13-17)$. Two hard-to-reach populations at high risk for hepatitis $\mathrm{C}$ are First Nations (FNs) people and people in prison. FNs people in Canada are seven times more likely to be infected with HCV compared with those in the non-FNs population: it has been estimated that 34,900 (or $3.0 \%$ ) of FNs people were HCV-infected and 6,300 (18.7\%) of incarcerated persons were HCV-infected $(13,14,18-20)$. Saskatchewan (SK) has the highest burden of HCV infection in FNs people (1-12,21-23).
There are multiple factors associated with this high burden, including access to testing, health care providers and treatment $(9,10,21,22)$. These access issues predominantly relate to geographical remoteness, issues with transportation, education and awareness, and a health care system designed around urban health $(1,2,8-12,21-23)$.

There are significant limitations in HCV surveillance; and despite this, a continuous and rising burden of HCV has been documented in Saskatchewan FNs communities as well as correctional facilities where FNs people are over represented $(1-5,11,12)$. Furthermore, $21 \%-44 \%$ of those chronically-infected are not aware of their HCV status $(2,24,25)$.

In recent years, new curative Direct Acting Agents (DAA) have revolutionized HCV treatment and have brought hope of possible elimination of $\mathrm{HCV}$ and associated liver diseases. But to deliver these promising treatments, individuals with HCV have to be accessed, identified, educated and properly treated. This paper highlights the burden of HCV in Saskatchewan, identifies challenges and barriers to care, and outlines ways Saskatchewan has been working to improve access to prevention and treatment services to promote liver health among FNs living on reserves. 


\section{HCV and Saskatchewan First Nations people}

Saskatchewan is a rapidly-growing province of over a million people. There are 70 distinct FNs in Saskatchewan and a total of 156,828 registered FNs people living in 84 geographically-isolated and geographically-dispersed communities. The community sizes range from 113 to 10,000 people. More than $50 \%$ of FNs people living on reserves in Saskatchewan, and $14 \%$ of these reserve communities are geographically isolated. Based on the population projection of Statistics Canada, one in every five people in Saskatchewan could be aboriginal by 2036 (7-10).

In addition to geographical isolation, FNs people in Canada also suffer from a high incarceration rate; estimated to be 1,024 per 100,000 or almost nine times higher for FNs people than for non-FNs people (14). While FNs people made up only $15 \%$ of the general population in Manitoba and Saskatchewan, they accounted for $64 \%$ of the provincial jail admissions in Manitoba and 76\% in Saskatchewan in 2000-2001 (14). At the same time, data suggests that FNs people are at increased risk for human immunodeficiency virus (HIV) and HCV infection and are infected at a younger age than non-FNs people. The high degree of mobility of FNs people between inner cities and rural areas may bring the risk of HIV and HCV to even the most remote communities $(3,14,18-20,24)$.

In addition, FNs people are over-represented in groups at high risk for HIV infection, in particular among injection drug users (IDUs). In Saskatchewan, a 2005 cross-sectional survey by Hennink et al. found that HCV is acquired relatively soon after IDUs begin injecting drugs (11). Within five years of beginning to inject, $50 \%-80 \%$ of IDUs were infected with HCV. As a result, many IDUs who become infected with HIV are already infected with HCV. Similarly Klein et al. found that HIV-HCV co-infected persons remained at markedly increased risk for death, despite treatment with antiretroviral therapy (15). A Canadian cohort study found that Aboriginal ethnicity and the female sex were associated with increased rates of HCV clearance, while HIV co-infection and illicit drug use were associated with decreased clearance rates (3). To further complicate identification and treatment of HCV-infected individuals, approximately $50 \%-85 \%$ of those who remain infected will progress to chronic infection but may be asymptomatic for decades.

\section{The challenges}

\section{HCV surveillance}

In Canada, HCV is a notifiable disease. Complete and timely surveillance of HCV data is essential for early identification and response to $\mathrm{HCV}$ outbreaks to minimize transmission and to implement evidenced-based prevention strategies. But in FNs communities, complete and timely surveillance is not always possible. In addition, national surveillance data are insufficient for determining the number of cases of hepatitis $C$ among FNs populations, largely because many provinces do not collect information according to ethnicity (1-5,7-15). As a result, information regarding ethnicity has been confined to population groups already at high risk for acquisition of blood borne pathogens (such as prison inmates and IDU) (3). Although FNs peoples are considered to bear the highest burden, there is a paucity of data.

Some statistics for FN communities are available federally through the First Nations and Inuit Health Branch (FNIHB) in partnership with the communities and the province. According to FNIHB-Health Canada, Saskatchewan Region, in 2015 the reported HCV new seropositive rates for FNs on-reserve communities were $372.0,186.7$, and 129.0 cases per 100,000 population in southern, central and northern FNs communities respectively. In 2015, these rates were six times, three times and two times higher than the provincial HCV rate (62.7 cases per 100,000), respectively.

In 2016, reported rates continued to increase, with the HCV new seropositivity rates of 401.2 cases per $100,000,211.6$ cases per 100,000 and 130.0 cases per 100,000 for the southern, central and northern communities, respectively (see Figure 1). HCV rates also increased markedly in the southern Saskatchewan FNs communities in the past years.

Figure 1: Saskatchewan hepatitis C rates in First Nations on reserves, by region, 2012 to 2016

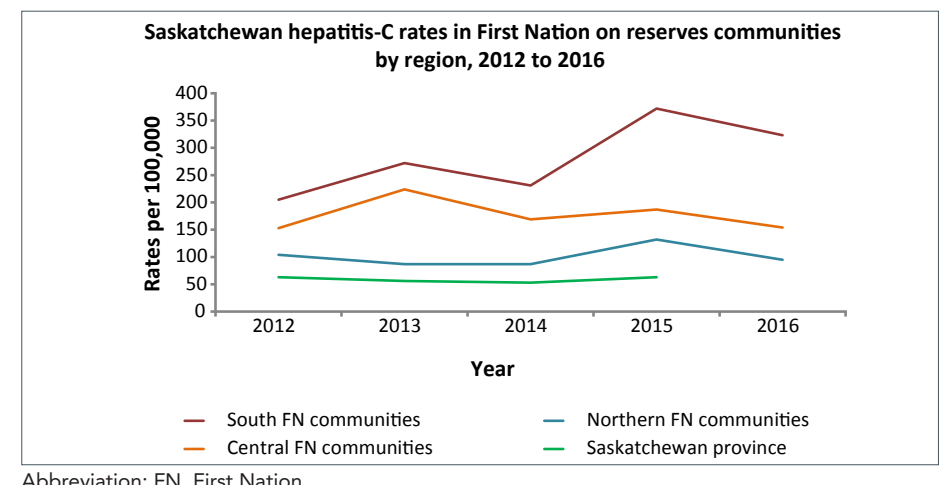

Abbreviation: FN, First Nation

In 2016, the majority of the HCV cases in Saskatchewan FNs communities were males (66\%) and many (33\%) of the HCV cases diagnosed were $30-39$ years of age (7-10). This is in contrast to Canadian data where the age range of HCV cases is older $(3,25)$.

\section{Access to HCV treatment and prevention programs}

Access to testing is not available in the some of FN communities in Saskatchewan and many do not have access to primary care (7-10,13-17,26). Furthermore for FNs on reserves, if the diagnosis is made off reserve where a local address is used, then the burden on reserves will be under represented. Mobility also leads to significant difficulty in locating patients and hence many are lost to follow up. Indeed, many do not get a confirmatory viral load diagnosis and many are not even aware of their infection.

Non-Insured Health Benefits (NIHB) program in Health Canada was one of the first plans to cover direct acting antiviral treatment for HCV for FNs and Inuit patients. Significant barriers related to poverty, communication and remoteness for FNs on reserves have impeded access to any curative therapy. Treatment requires access to fibroscan or staging of liver disease typically available in tertiary care centres only, as well as an HCV 
treatment provider, who is available predominantly in major urban centres. Further, untreated viremia, combined with limited access to harm reduction services, only continues to exacerbate the rates through on-going active transmission.

Liver transplantation is problematic, as access to specialized hepatitis clinics and treatment is limited in Saskatchewan and a growing number of patients are referred to the Edmonton liver transplant program (20,22,23,27-29). In Saskatchewan only 28 patients have received liver transplants since 2008 and 225 are currently on the waiting list for a transplant $(22,23,26)$.

\section{The innovations}

\section{Preventive services}

The FNs communities are at various stages in terms of capacities and their response to the increasing HCV (and HIV) rates. Currently there are 21 harm reduction (including needle exchange programs) sites operating on reserves in Saskatchewan. These programs are linked to screening, mental health and addiction services and other family support programs. The FNIHB-Saskatchewan Region (Indigenous Services Canada), is working closely with all partners to support communities adapting Sexually Transmitted and Bloodborne Infection (STBBI) Know Your Status models of care.

The culturally grounded Know Your Status model was initially implemented by two Saskatchewan FN communities, and involves 1) community engagement, education, prevention and harm reduction and 2) clinical management surveillance and evaluation. Key personnel of the Know Your Status program include those specializing in community health, harm reduction outreach, lab services, primary care, infectious disease,

prevention and awareness, and cultural support $(7-10,21,26,30)$. The Know Your Status proved to be a highly effective model of HIV care for on reserve communities. In 2015 it achieved the United Nations goal of 90/90/90 (90\% of people living with HIV know their status (31), $90 \%$ of people who know their status are accessing treatment and $90 \%$ of people on treatment have a suppressed viral load) $(7-10,21,26,30)$. In partnership with Saskatchewan FNs, similar programs are currently being rolled out to more than $\mathbf{5 0}$ other communities. This model of care is now being extended to include HCV and other STBBIs.

To support the 84 FNs communities across Saskatchewan, there are currently 12 nursing stations on reserves in the north, 23 sites operating in south central communities that offer HIV/HCV Point of Care Testing and 13 specialized mobile nursing or outreach teams across Saskatchewan that provide program support.

\section{Mobile hepatitis C clinics}

There has been a change in approach to address hepatitis $C$ in FN communities in Saskatchewan over the past two years. A partnership has been established between public health, FNs communities, FNs leaders, labs and clinical providers to bring testing and care directly to remote FNs communities through the use of mobile hepatitis $C$ clinics, which brings testing, education, fibroscans and DAA treatment directly to the Saskatchewan FNs communities.
These mobile clinics are multidisciplinary in nature. These clinics are advertised in advance and invite community members with $\mathrm{HCV}$ or those who engage in risk behaviours to attend. They provide one-on-one educational and in depth counselling sessions. Testing and assessment of patient's health/liver conditions are also undertaken and, where indicated, plans are made for integrated care and referral for community-based treatment the same day. Moreover, awareness and expertise developed locally has allowed communities to take ownership of this comprehensive approach to HCV infection, its underlying risk factors and the health of their members by providing culturally-sensitive and accessible care in a team-based model.

These mobile in-community HCV clinics have been named "Liver Health Days". They have not only attracted the interest of FNs people affected with HCV but have also improved treatment uptake, health outcomes and adherence rates. The number of these mobile clinics is increasing as more FNs communities take ownership and leadership in the prevention programs. Community leadership, staff (e.g., community health nurses, registered nurses and nurse practitioners) trained in liver health and cultural safety in the provision of HCV care are the key ingredients of success in this regard. Culturally safe or appropriate care means that all members of the health care system are aware of the history and impact of intergenerational trauma and the current challenges (such as racism) that FNs people experience when trying to access health care, and that they do everything possible to ensure that the care they provide is respectful, comprehensive and holistic.

\section{Injection drug use (IDU) and addressing determinants of health}

As IDU is a primary risk factor for acquiring and for the transmission of $\mathrm{HCV}$, addressing drug addiction and associated mental health issues are critical to the HCV response. Monitoring drug and addiction trends at the community level is an effective tool. While offering community-based services for HCV infection, awareness of factors that promote resilience and addressing determinants of health such as intergenerational trauma from a history of colonization and residential schools, racism, overcrowding, education and literacy, social exclusion and gender inequality, could help FNs people access to health care services $(16,17)$.

\section{Discussion}

The HCV has become a major global public health issue that is reflected in the rising burden of HCV in Saskatchewan FNs people on reserves. Until recently, FNs people living on reserves in Saskatchewan have not been accessing treatment. Recent community-based programs innovations, such as the mobile hepatitis C clinic and the community-driven HIV/HCV Know Your Status program, which offer onsite testing/counselling, harm reduction services, diagnostics and treatment, are becoming invaluable in addressing the HCV situation on FN reserves $(7-10,21,26,30,32)$.

In 2016, Canada, along with member states of the World Health Organization, adopted the first global strategy on viral hepatitis with a goal to eliminate viral hepatitis as a major public health 
threat by 2030 and that everyone living with viral hepatitis has access to safe, affordable and effective treatment (33). The strategy identified underdiagnosis as a key barrier to eliminating $\mathrm{HCV}(2,6,34)$. Adopting best practices and innovative models that engage clients in prevention, early diagnosis and treatment of $\mathrm{HCV}$ is critical to stopping the transmission in all settings, whether it is on or off reserve. Given the high level of HCV in IDU, attention has focussed on this subgroup of the population. A recent meta-analysis of strategies effective at reducing $\mathrm{HCV}$ sero-conversion found that employing a combination of interventions was most effective at reducing HCV transmission among IDU $(24,25,32,35-41)$ before the onset of cirrhosis (fibrosis stage F0-F3) have fewer long term HCV-related complications than those who achieve sustained virologic response (SVR) after the onset of cirrhosis (fibrosis stage F4) $(2,4)$. Early intervention has been found to be effective not only in preventing progression of liver disease but also in stopping the spread of infection in communities.

\section{Next steps}

Based on the success of Saskatchewan's STBBI Know Your Status approach, expansion of similar community-designed and culturally appropriate programs to other FNs reserves across Saskatchewan will help to improve treatment and stop transmission of HCV. This could have the added benefit of improving surveillance information and providing good outcome data.

Partnerships between on and off reserve programs are needed to optimize care and provide outreach support and awareness campaigns across various national and provincial jurisdictions. It will be important to address attitudes that may interfere with the prevention, treatment and care activities, and to reduce HCVand HIV-related stigma and discrimination across the spectrum of services.

Due to the alarmingly high levels of HCV in prison inmates, particularly in the FNs inmates, targeted HCV initiatives by and for FNs inmates are needed in Saskatchewan. The FNs HCV programs already present at the community level could be linked to care in prisons. Interventions targeting modifiable risk factors, such as substance use, smoking, proper adherence to antiretroviral therapy and timely provision of HCV therapy could substantially reduce complications and lower death rates.

Further research is needed to evaluate the extent and the determinants associated with HCV infection, obtain population-based estimates of HCV prevalence and incidence in the Saskatchewan FNs population, develop FN community-led programs to prevent new infection, better understand $\mathrm{HCV}$ infection, and implement more effective methods of addiction management in $\mathrm{HCV}$-positive patients.

\section{Conclusion}

There are multiple factors associated with the high rates of HCV in FNs communities, including barriers to access preventive services, early diagnosis and treatment. These access issues predominantly relate to remoteness, transportation, education and awareness and a health care system designed around urban health. Instigation of new and innovative ways of delivering information and services, such as the mobile hepatitis $C$ clinic and the community-driven STBBI Know Your Status model of care, are proving invaluable in remote FNs communities. Extending these programs to other FNs communities and to the prison population, which often has a disproportionately high population of both FNs individuals and HCV-infected individuals, could prove to be invaluable in addressing HCV infection and helping Canada meet the global goal of HCV elimination.

\section{Authors' statement}

Dr. Skinner and Dr. Khan collaborated with Chief Cote and all the content reflected in this article come from the programs delivered in direct partnership with First Nations communities.

\section{Conflict of interest}

None.

\section{Funding}

First Nations and Inuit Health Branch of Indigenous Services Canada (FNIHB) provides funds for various programs and services in First Nations on reserves in Saskatchewan. Specifically, FNIHB supports Dr. Skinner and his program delivery on reserves.

\section{Acknowledgements}

We would like to acknowledge the support from Mustafa Andkhoie, Epidemiologist and Dr. Tom Wong, Chief Medical Health Officer of First Nations Inuit Health Branch, Health Canada.

\section{References}

1. McDevitt N, Salamone G. Critical years ahead in the fight against HCV. Montreal (QC); McGill University Health Centre; July 2016. https://muhc.ca/our-stories/article/critical-yearsahead-fight-against-hepatitis-c-virus

2. Cadieux G, Sachdeva H. Toward ending hepatitis $\mathrm{C}$ virus infection: what are the next steps? CMAJ 2017 Apr;189(16):E583-4. http://dx.doi.org/10.1503/cmaj.170274. PubMed (https://www.ncbi.nlm.nih.gov/pmc/articles/ PMC5403640/)

3. Uhanova J, Tate RB, Tataryn DJ, Minuk GY. The epidemiology of hepatitis $C$ in a Canadian Indigenous population. Can J Gastroenterol 2013 Jun;27(6):336-40. http://dx.doi. org/10.1155/2013/380963. PubMed (https://www.ncbi.nlm.nih. gov/pmc/articles/PMC3684368/)

4. D'Ambrosio R, Della Corte C, Colombo M. Hepatocellular carcinoma in patients with a sustained response to anti-hepatitis C Therapy. Int J Mol Sci 2015 Aug;16(8):19698_ 712. http://dx.doi.org/10.3390/ijms160819698. PubMed (https://www.ncbi.nlm.nih.gov/pubmed/26295392)

5. Mohd Hanafiah K, Groeger J, Flaxman AD, Wiersma ST. Global epidemiology of hepatitis $C$ virus infection: new estimates of age-specific antibody to HCV seroprevalence. Hepatology 
2013 Apr;57(4):1333-42. http://dx.doi.org/10.1002/hep.26141. PubMed (https://www.ncbi.nlm.nih.gov/pubmed/23172780)

6. World Health Organization. Hepatitis C (fact sheet; updated April 2018). WHO: 2014. www.who.int/mediacentre/ factsheets/fs164/en/

7. Indigenous Services Canada. First Nations Health Status Reports 2012 - Saskatchewan Region. Ottawa (ON); Health Canada: 2015. http://publications.gc.ca/collections/ collection_2015/sc-hc/H34-293-2015-eng.pdf

8. Statistics Canada. Projection of the Aboriginal population and households in Canada, 2011 to 2036. Ottawa (ON); Statistics Canada: 2015. www.statcan.gc.ca/daily-quotidien/150917/ dq150917b-eng.htm

9. Khan I. View point: First Nations making big gains in HIV/ AIDS. Saskatoon Star Phoenix; December 6, 2016. http:// thestarphoenix.com/opinion/columnists/1206-edit-khan-view

10. Khan I. First Nations Forum focuses on "Know Your Status Program" success to combat HIV. Global News; February 15, 2017. https://globalnews.ca/news/3247047/first-nations-forumfocuses-on-know-your-status-program-success-to-combat-hiv/

11. Hennink M, Abbas Z, Choudhri Y, Diener T, Lloyd K, Archibald CP, Cule S. Risk behaviours for infection with HIV and hepatitis $C$ virus among people who inject drugs in Regina, Saskatchewan. Can Commun Dis Rep 2007 Mar;33(5):53-9. PubMed (https://www.ncbi.nlm.nih.gov/pubmed/17520768)

12. Grad R, Thombs BD, Tonelli M, Bacchus M, Birtwhistle $\mathrm{R}$, Klarenbach $\mathrm{S}$, Singh H, Dorais $\mathrm{V}$, Holmes NM, Martin WK, Rodin R, Jaramillo Garcia A; Canadian Task Force on Preventive Health Care. Recommendations on hepatitis C screening for adults. CMAJ 2017 Apr;189(16):E594-604. http://dx.doi.org/10.1503/cmaj.161521. PubMed (https://www. ncbi.nlm.nih.gov/pubmed/28438952)

13. Public Health Agency of Canada. Modelling the incidence and prevalence of hepatitis $\mathrm{C}$ infection and its sequelae in Canada, 2007. Ottawa (ON); PHAC: 2007. https://www.canada.ca/ en/public-health/services/infectious-diseases/surveillanceepidemiology-sexually-transmitted-infections-hep-b-c/ modelling-incidence-prevalence-hepatitis-infection-sequelae. html

14. Canadian HIV/AIDS legal network. HIV and hepatitis $C$ in prisons: the facts (Position papers 1-13). http://librarypdf.catie. ca/PDF/P48/HIVandhepatitisCinprisons.pdf

15. Klein MB, Rollet-Kurhajec KC, Moodie EE, Yaphe S, Tyndall M, Walmsley S, Gill J, Martel-Laferriere V, Cooper C; Canadian Co-infection Cohort Investigators. Mortality in HIV-hepatitis C co-infected patients in Canada compared to the general Canadian population (2003-2013). AIDS 2014 Aug;28(13):1957-65. http://dx.doi.org/10.1097/ QAD.0000000000000377. PubMed (https://www.ncbi.nlm.nih. gov/pubmed/25259703)

16. Mikkonen J, Raphael D. Social Determinants of Health: The Canadian Facts. Toronto (ON); York University School of Health Policy and Management: 2010. http://thecanadianfacts.org/ the_canadian_facts.pdf

17. Cooper CL, Giordano C, Mackie D, Mills EJ. Equitable access to HCV care in HIV-HCV co-infection can be achieved despite barriers to health care provision. Ther Clin Risk Manag 2010 Apr;6:207-12. http://dx.doi.org/10.2147/TCRM. S9951. PubMed (https://www.ncbi.nlm.nih.gov/pmc/articles/ PMC2861442/)

18. Public Health Agency of Canada. Epidemiology of acute hepatitis $C$ infection in Canada: Results from the enhanced hepatitis strain surveillance system (EHSSS). Ottawa (ON); PHAC: 2009. http://publications.gc.ca/collections/ collection_2011/aspc-phac/HP40-41-2010-eng.pdf

19. Wylie JL, Shah L, Jolly AM. Demographic, risk behaviour and personal network variables associated with prevalent hepatitis
$C$, hepatitis $B$, and HIV infection in injection drug users in Winnipeg, Canada. BMC Public Health 2006 Sep;6:229. http:// dx.doi.org/10.1186/1471-2458-6-229. PubMed (https://www. ncbi.nlm.nih.gov/pmc/articles/PMC1586015/)

20. Buxton JA, Yu A, Kim PH, Spinelli JJ, Kuo M, Alvarez M, Gilbert $M$, Krajden M. HCV co-infection in HIV positive population in British Columbia, Canada. BMC Public Health 2010 Apr;10:225. http://dx.doi.org/10.1186/1471-2458-10-225. PubMed (https://www.ncbi.nlm.nih.gov/pubmed/20429917/)

21. Khan I, Ndubuka N, Stewart K, McKinney V, Mendez I. The use of technology to improve health care to Saskatchewan's First Nations communities. Can Commun Dis Rep 2017 Jun;43(6):120-4. http://dx.doi.org/10.14745/ccdr.v43i06a01. PubMed (https://www.ncbi.nlm.nih.gov/pmc/articles/ PMC5764719/).

22. McAdam B. A second chance at life: organ donation in Sask. Mar 31, 2015. paNOW, Prince Albert (SK). http://panow.com/ article/507610/second-chance-life-organ-donation-sask

23. Canadian Blood Services. Organ donation and transplantation in Canada. System Progress Report 2006-2015. Ottawa (ON); CBS; 2016. https://blood.ca/sites/default/files/ODT_Report. pdf

24. Centre for Communicable Diseases and Infection Control and Control Branch Public Health Agency of Canada. Hepatitis C in Canada, 2005-2010 Surveillance Report. Ottawa (ON);PHAC: 2011. http://publications.gc.ca/collections/collection_2012/ aspc-phac/HP40-70-2012-eng.pdf

25. Trubnikov M, Yan P, Archibald C. Estimated prevalence of Hepatitis C Virus infection in Canada, 2011. Can Commun Dis Rep 2014 Dec;40(19):429-36. PubMed (https://www.ncbi.nlm. nih.gov/pubmed/29769874/)

26. Ibrahim K, Skinner S. Know your HIV status: outcome of multidisciplinary HIV testing and care project in Saskatchewan's First Nations Community. Proceedings 21st Annual Canadian Conference on HIV/ AIDS Research - CAHR 2012 (Montreal QC). https://www.cahr-acrv.ca/wp-content/uploads/2012/09/ CAHR-PROG-2012-EFO-5.pdf

27. Galabuzi G. The Social Determinants of Health: Canadian Perspectives. 3rd edition. Ed. Dennis Raphael. Toronto (ON):Canadian Scholars' Press; 2004. Chapter 17, Social Exclusion; p. 388-623.

28. Mikkonen J, Raphael D. Social Determinants of Health: The Canadian Facts. Toronto (ON); York University School of Health Policy and Management: 2010. http://thecanadianfacts.org/

29. Patrick DM, Tyndall MW, Cornelisse PG, Li K, Sherlock $\mathrm{CH}$, Rekart ML, Strathdee SA, Currie SL, Schechter MT, O'Shaughnessy MV. Incidence of hepatitis C virus infection among injection drug users during an outbreak of HIV infection. CMAJ 2001 Oct;165(7):889-95. PubMed (https:// www.ncbi.nlm.nih.gov/pmc/articles/PMC81496/)

30. Testing clinic in Kamsack aimed to help reduce area's high rate of HIV infection. Kamsack Times; Sept 4, 2017. www. kamsacktimes.com/news/testing-clinic-in-kamsack-aimed-tohelp-reduce-area-s-high-rate-of-hiv-infection-1.22345436

31. UNAIDS. 2015 Progress report on the global plan towards the elimination of new HIV infections among children and keeping their mothers alive. http://www.unaids.org/en/resources/ documents/2015/JC2774_2015ProgressReport_GlobalPlan

32. New outreach centre opened in Kamsack aims to combat mental illness, HIV and addictions. Kamsack Times; October 17 2016. www.kamsacktimes.com/news/local-news/new-outreachcentre-opened-in-kamsack-aims-to-combat-mental-illness-hivand-addictions-1.2366703

33. World Health Organization. Global health sector strategy on viral hepatitis 2016-2021. Towards ending viral hepatitis. WHO; 2016. http://apps.who.int/iris/handle/10665/246177 
34. Marmot M, Friel S, Bell R, Houweling TA, Taylor S; Commission on Social Determinants of Health. Closing the gap in a generation: health equity through action on the social determinants of health. Lancet 2008 Nov;372(9650):1661-9. http://dx.doi.org/10.1016/S0140-6736(08)61690-6. PubMed (https://www.ncbi.nlm.nih.gov/pubmed/18994664)

35. Hagan H, Pouget ER, Des Jarlais DC. A systematic review and meta-analysis of interventions to prevent hepatitis $C$ virus infection in people who inject drugs. J Infect Dis 2011 Jul;204(1):74-83. http://dx.doi.org/10.1093/infdis/jir196. PubMed (https://www.ncbi.nlm.nih.gov/pubmed/21628661)

36. Abou-Saleh $M$, Davis $P$, Rice $P$, Checinski $K$, Drummond $C$, Maxwell D, Godfrey C, John C, Corrin B, Tibbs C, Oyefeso A, de Ruiter M, Ghodse H. The effectiveness of behavioural interventions in the primary prevention of hepatitis $\mathrm{C}$ amongst injecting drug users: a randomised controlled trial and lessons learned. Harm Reduct J 2008 Jul;5:25. http://dx.doi. org/10.1186/1477-7517-5-25. PubMed (https://www.ncbi.nlm. nih.gov/pubmed/18671853)

37. Razali K, Thein HH, Bell J, Cooper-Stanbury M, Dolan K, Dore G, George J, Kaldor J, Karvelas M, Li J, Maher L, McGregor S, Hellard M, Poeder F, Quaine J, Stewart K, Tyrrell H, Weltman M, Westcott O, Wodak A, Law M. Modelling the hepatitis $C$ virus epidemic in Australia. Drug Alcohol Depend 2007 Dec;91(2-3):228-35. http://dx.doi.org/10.1016/j. drugalcdep.2007.05.026. PubMed (https://www.ncbi.nlm.nih. gov/pubmed/17669601)

38. van den Berg CH, Smit C, Bakker M, Geskus RB, Berkhout B, Jurriaans S, Coutinho RA, Wolthers KC, Prins M. Major decline of hepatitis $C$ virus incidence rate over two decades in a cohort of drug users. Eur J Epidemiol 2007;22(3):183-93. http:// dx.doi.org/10.1007/s10654-006-9089-7. PubMed (https:// www.ncbi.nlm.nih.gov/pubmed/17334821)

39. Hagan $H$, Thiede $H$, Des Jarlais DC. Hepatitis $C$ virus infection among injection drug users: survival analysis of time to seroconversion. Epidemiology 2004 Sep;15(5):543-9. http:// dx.doi.org/10.1097/01.ede.0000135170.54913.9d. PubMed (https://www.ncbi.nlm.nih.gov/pubmed/15308953)

40. Nancy Macdonald. Canada's prisons are the 'new residential schools' - A months-long investigation reveals that at every step, Canada's justice system is set against Indigenous people. Macleans 2016;18(February). www.macleans.ca/news/canada/ canadas-prisons-are-the-new-residential-schools/

41. Mamneet M. Growing Crises of HIV/AIDS, Hepatitis C, and Chronic Mental Illnesses Among Prison Populations in Canada: Implications for Policy Prescriptions With a Special Focus on Aboriginal Inmates. Manitoba Policy Perspectives. 2014; 1(1):82-102. https://umanitoba.ca/centres/mipr/media/6._ HIVAIDS_Manghera.pdf

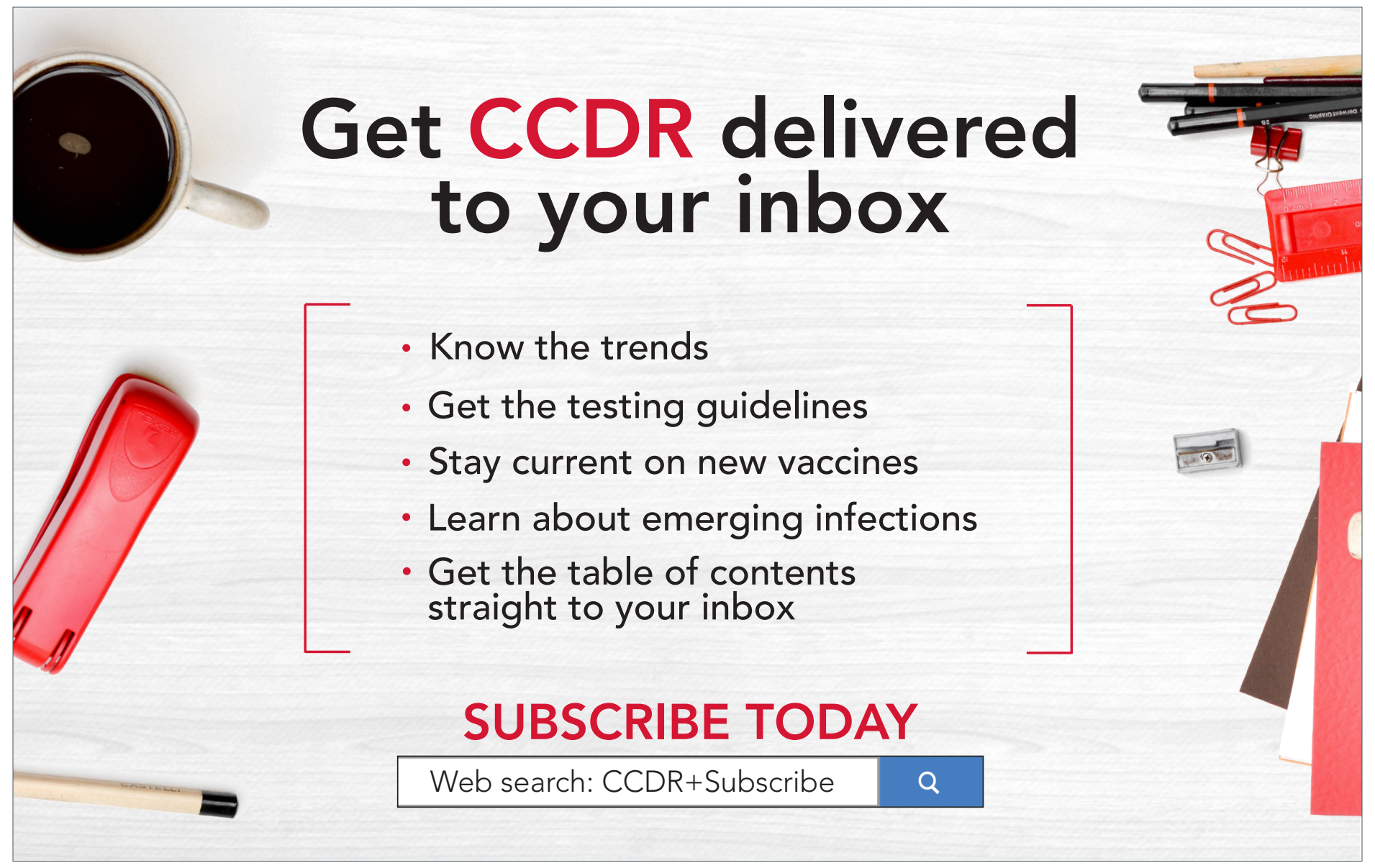

